\title{
Detección de resistencia primaria en pacientes chilenos infectados por VIH
}

\author{
William Acevedo ${ }^{1 a}$, Ana María G allardo ${ }^{1 b}$, José G alaz ${ }^{1 a}$, \\ Alejandro Afani ${ }^{1}$, Esteban Cortés ${ }^{2,3}$ \\ Detection of primary antiretroviral \\ resistance in Chilean patients \\ recently infected with human \\ immunodeficiency virus (HIV)
}

Background: In countries with universal access to antiretroviral therapy, a progressive increase in the number of patients that are infected with resistant virus, is observed. Aim: To detect the presence of primary resistance to antiretroviral drugs among patients with a recent diagnosis of HIV infection. Material and methods: Twenty five male patients aged 25 to 45 years, with a diagnosis of a recent HIV infection, done between 2004 and 2005, were studied. Genotypic resistance to antiretroviral drugs was studied using the Genetic Resistance Test TRUGENE ${ }^{\circledR}$ from Bayer. Results: Resistance mutations were detected in 10 patients. All had an university title or had university studies. All lived in northeastern Santiago and had risky sexual behaviors while traveling abroad. Seven mutations were detected in reverse transcriptase. Of these, three were associated to a high resistance level and four, to an intermediate or low resistance, were also detected. Conclusions: A high frequency of genotypic resistance was detected in this group of Chilean patients recently infected with HIV. A higher socioeconomic status and lifestyle could have influenced these results (Rev Méd Chile 2007; 135: 1406-13).

(Key words: Antiretroviral agents; Drug resistance, multiple, viral; HIV)

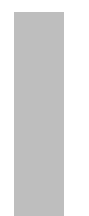

Recibido el 3 de abril 2007. Ace
${ }^{1}$ Sección Inmunología, Hospita
Interna, Hospital Clínico Univers
María, Chile.
aBioquímico.
becaria Inmunología Clínica.

T a pandemia del SIDA ha crecido invariableLmente desde el primer caso descrito hace ya

Correspondencia a: William Marcos Acevedo Muñoz. Laboratorio Medicina Molecular. Hospital Clínico Universidad de Chile. Santos Dumont 999, 5 piso E, Of. E-520. Independencia, Santiago. Fono: 9788848. Email: wacevedo@redclinicauchile.cl wacevedo@vtr.net
20 años, con 25 millones de individuos fallecidos desde $1981^{1}$. Actualmente, más de 40 millones de personas en el mundo están infectadas con el VIH (Virus de la inmunodeficiencia humana). En el año 2006 hubo 4,3 millones de nuevas infecciones y de éstas, 2,6 millones (65\%) ocurrieron en África Subsahariana. Se estima que en el año 2006, casi 3 millones de personas murieron por causas asociadas a la infección VIH/SIDA ${ }^{1}$. 
La epidemia de VIH-SIDA se inició en Chile en 1984, con 6 personas, distribuidas en las regiones V, VIII y Metropolitana. Todos estos casos eran hombres entre los 27 y 42 años. En 1985 la Región Metropolitana notifica la primera mujer en el país. Entre los años 1984 y 2004 han muerto 5.043 personas por SIDA en nuestro país, y hasta el año 2005, se han notificado 15.870 casos de VIH o SIDA $^{2}$.

La terapia antirretroviral altamente activa (TAR) ha cambiado la historia natural de la infección VIH/SIDA, al retardar la evolución de la enfermedad y mejorar la calidad de vida de los individuos infectados. Los países desarrollados han implementado esta modalidad terapéutica masivamente en su población infectada en seguimiento, con resultados muy favorables. En Chile, desde $2002 \mathrm{el}$ Ministerio de Salud proporciona terapia antirretroviral a todos los pacientes con infección VIH/SIDA que cumplan los criterios para utilizarla, con una cobertura actual del $100 \%^{2,3}$.

Uno de los principales problemas en la actualidad es el fracaso terapéutico y, dentro de éste, el aumento de resistencia a drogas antirretrovirales ${ }^{4}$. Este problema se origina por la asociación de las características propias del virus (variabilidad genética, latencia y reactivación, adaptación a puertas de entrada, infección de reservorios), junto a una inadecuada supresión viral (adherencia, farmacocinética) y uso de monoterapia y biterapia previos ${ }^{4}$. La menor susceptibilidad del virus a las drogas está asociada a mutaciones en los genes que codifican, entre otros, para las enzimas transcriptasa reversa y proteasa viral. La resistencia viral que aparece bajo la presión de las drogas antirretrovirales en una persona en tratamiento, se ha denominado resistencia secundaria. La resistencia primaria se observa en los pacientes vírgenes a tratamiento como resultado de la transmisión de virus resistente ${ }^{4}$. La resistencia primaria ha tenido un importante aumento en el mundo. Los índices de resistencia primaria son muy altos en Estados Unidos de Norteamérica y Europa, probablemente debido a que han tenido acceso por más tiempo a las drogas antirretrovirales 5 . En regiones que presentan niveles de resistencia primaria mayores a 5\%-10\% se recomienda el uso de un test de resistencia previo a la indicación de la primera terapia. En relación a este punto, hoy se dispone de dos metodologías diferentes de aproximación a la resistencia del virus a las drogas: los ensayos de resistencia genotípicos y fenotípicos. Los tests genotípicos detectan mutaciones en el genoma viral asociadas a la aparición de resistencia, mientras que los tests fenotípicos miden la concentración de fármaco necesaria para poder inhibir la replicación viral in vitro ${ }^{7}$.

El test de genotipificación es un ensayo basado en la amplificación genética mediante la reacción en cadena de la polimerasa (PCR), de las regiones del genoma del virus implicadas en el desarrollo de resistencia, para luego analizar su secuencia nucleotídica. La resistencia genotípica es el término utilizado para describir la presencia de mutaciones que se traducen en una reducción de la sensibilidad a uno o más fármacos. Esta técnica consta de dos etapas: la amplificación de la región específica por PCR común a los test disponibles y la detección de mutaciones que se realiza por tres técnicas diferentes: secuenciación de ADN, hibridización y line probe assay. La secuenciación de ADN es el método de referencia. Mediante éste se determina la secuencia de nucleótidos de las regiones del genoma amplificado, las que posteriormente se comparan con secuencias de referencia del VIH-1 para determinar la presencia de las diferentes mutaciones. El test HIV-1 TrueGene ${ }^{\mathrm{TM}}$ (Bayer S.A.) utiliza esta técnica y fue aprobado por la Food and Drugs Administration (FDA) de Estados Unidos de Norteamérica (EE.UU), el año 2000, para uso clínico $^{7,8}$. En Chile, desde 2002 el Ministerio de Salud recomienda el uso del test de resistencia genética en caso de falla terapéutica.

La prevalencia de resistencia primaria varía mucho en los distintos países. Los estudios para evaluar la prevalencia de resistencia primaria en una determinada población de infectados deben realizarse de regla en individuos en que se tenga la certeza de que adquirieron la infección recientemente y que no hayan recibido terapia antirretroviral. Además de esto, existen otras variables que son importantes de analizar cuando se estudia un grupo de pacientes, como son los antecedentes epidemiológicos y socioculturales, que pueden estar jugando roles importantes en una determinada comunidad.

El objetivo de este estudio es detectar la presencia de resistencia primaria en pacientes con diagnóstico reciente de infección por VIH bien documentados, y caracterización epidemiológica de los mismos. 


\section{MATERIAL Y MÉTODO}

Entre 2004 y 2005 se seleccionaron veinticinco pacientes chilenos que fueron diagnosticados con infección por VIH en el Hospital Clínico de la Universidad de Chile y confirmados en el Centro de Referencia del Instituto de Salud Pública, mientras cursaban una infección primaria sintomática o sospecha de infección reciente, determinada mediante serologías previas negativas en un período previo no mayor a 12 meses. Se incluyeron pacientes mayores de 18 años, que no hubieran recibido antes drogas antirretrovirales o que hubiesen comenzado algún esquema de tratamiento según recomendaciones internacionales actuales del Centers for Disease Control (CDC) $)^{3,8}$. Se analizaron también características tales como edad, sexo, vía de transmisión de la infección, carga viral, domicilio, nivel educacional y actividad laboral.

Todos los pacientes fueron estudiados en el Laboratorio de Medicina Molecular del Hospital Clínico de la Universidad de Chile. La carga viral de VIH se determinó mediante el sistema Amplicor $1.5^{\circledR}$ de Roche Molecular Diagnostics, y la Genotipificación mediante el Test de Resistencia Genética TRUGENE $^{\circledR}$ de Bayer. En este ensayo se identificaron mutaciones en los genes de la Proteasa y
Transcriptasa Reversa virales mediante secuenciamiento directo y visualización en geles de acrilamida-poliacrilamida al 6\%. La interpretación de las mutaciones detectadas está basada en el algoritmo de interpretación clínica GuideLines $8.0^{\circledR}$.

\section{Resultados}

Características de los pacientes. De un total de 25 pacientes estudiados la edad promedio fue 35 años (25-45 años), 100\% (25/25) de sexo masculino. El $76 \%(19 / 25)$ de los pacientes presentaba conducta homosexual o bisexual. La carga viral promedio al momento del diagnóstico fue de 161.910 copias virales (rango 12.000-560.000) (Tabla 1).

Análisis genotípico. Se detectaron mutaciones de resistencia en diez de los veinticinco pacientes estudiados (Tabla 2). Todos eran homo-bisexuales $100 \%(10 / 10)$. Los pacientes homosexuales (9/10) tenían un ELISA negativo para VIH en el último año previo al presente diagnóstico. El paciente bisexual (1/10) fue diagnosticado en etapa de seroconversión. Todos los pacientes describieron un comportamiento sexual de riesgo mientras visitaban otros países durante el último año, con motivo de vacaciones o actividades profesionales (Figura 1).

Tabla 1. C aracterísticas generales de los pacientes

\begin{tabular}{|c|c|}
\hline Característica & Pacientes $(n=25)$ \\
\hline \multicolumn{2}{|l|}{ Edad (años) } \\
\hline Promedio & 35 \\
\hline Rango & $25-45$ \\
\hline \multicolumn{2}{|l|}{ Género } \\
\hline Masculino & $(100 \%)$ \\
\hline Femenino & 0 \\
\hline \multicolumn{2}{|l|}{ Conducta de Riesgo Declarada } \\
\hline Sexual (homosexual) & $16 \quad(64 \%)$ \\
\hline Sexual (bisexual) & $3 \quad(12 \%)$ \\
\hline Sexual (heterosexual) & $(24 \%)$ \\
\hline Uso drogas endovenosas & $1^{*} \quad(4 \%)$ \\
\hline \multicolumn{2}{|l|}{ Carga Viral (copias/ml) } \\
\hline Promedio & 161.910 \\
\hline Mediana & 79.350 \\
\hline Rango & $12.000-560.000$ \\
\hline
\end{tabular}

*Paciente homosexual 
Tabla 2. M utaciones relevantes encontradas

\begin{tabular}{|c|c|c|c|c|c|c|}
\hline \multirow[t]{2}{*}{ Paciente } & \multirow[t]{2}{*}{ Nacionalidad } & \multirow{2}{*}{$\begin{array}{l}\text { Edad } \\
\text { (años) }\end{array}$} & \multirow[t]{2}{*}{ Sexualidad } & \multirow{2}{*}{$\begin{array}{l}\text { País visitado } \\
\text { (Ciudad) }\end{array}$} & \multicolumn{2}{|c|}{ Mutación } \\
\hline & & & & & $\mathrm{TR}$ & Proteasa \\
\hline 1 & Chilena & 37 & Homosexual & $\begin{array}{l}\text { Argentina } \\
\text { (Buenos Aires) }\end{array}$ & - L10V, & M36I \\
\hline 2 & Chilena & 35 & Homosexual & $\begin{array}{l}\text { Ecuador } \\
\text { (Quito) }\end{array}$ & - & M36I \\
\hline 3 & Chilena & 42 & Homosexual & $\begin{array}{l}\text { España } \\
\text { (Madrid) }\end{array}$ & - & L63P \\
\hline 4 & Chilena & 33 & Homosexual & $\begin{array}{l}\text { México } \\
\text { (Ciudad de México) }\end{array}$ & - & K20R, L63P \\
\hline 5 & Chilena & 28 & Homosexual & $\begin{array}{l}\text { Brasil } \\
\text { (San Pablo-Río de Janeiro) }\end{array}$ & - & L63P \\
\hline 6 & Chilena & 32 & Homosexual & $\begin{array}{l}\text { Estados Unidos } \\
\text { (Boston, Nueva York) }\end{array}$ & $\begin{array}{l}\text { V75T, K103N } \\
\text { Y188C }\end{array}$ & L10V, L63P \\
\hline 7 & Chilena & 45 & Bisexual & $\begin{array}{l}\text { España } \\
\text { (Madrid, Barcelona, Ibiza) }\end{array}$ & D67N, K70R & M36I, L63P \\
\hline 8 & Chilena & 27 & Homosexual & $\begin{array}{l}\text { Brasil } \\
\text { (Río de Janeiro) }\end{array}$ & & $-\mathrm{A} 71 \mathrm{~V}$ \\
\hline 9 & Chilena & 38 & $\begin{array}{l}\text { Homosexual } \\
\text { Drogas endovenosas }\end{array}$ & $\begin{array}{l}\text { Holanda } \\
\text { (La Haya) }\end{array}$ & G190S & L63P \\
\hline 10 & Chilena & 35 & Homosexual & $\begin{array}{l}\text { Francia } \\
\text { (París, Marsella) }\end{array}$ & V179D & - \\
\hline
\end{tabular}

Un total de siete mutaciones fueron identificadas en la transcriptasa reversa (Tabla 3). Tres mutaciones asociadas a alto nivel de resistencia (K103N, G190S, Y188C), que confieren resistencia al grupo de los inhibidores no análogos de nucleósidos de la transcriptasa reversa (ITRNN); y cuatro mutaciones asociadas a resistencia intermedia/baja. D67N, K70R, V75T que disminuyen la sensibilidad del virus a

=Argentina (Buenos Aires)

=Ecuador (Quito)

=España (Madrid)

=México (Ciudad de México)

=Brasil (San Pablo-Río de Janeiro)

=Estados Unidos de Norteamérica (Boston, Nueva York)

=España (Barcelona, Ibiza, Madrid)

=Brasil (Río de Janeiro)

=Holanda (La Haya)

$10=$ Francia (París, Marsella)

Figura 1. Zonas de conducta de riesgo declarada y probable infección por VIH. 
Tabla 3. Frecuencia y relevancia de mutaciones encontradas

\begin{tabular}{|llll|}
\hline Mutaciones & & Pacientes $(\mathrm{n}=25)$ & Nivel de Resistencia \\
\hline Gen Transcriptasa Reversa & V179D & $1 \quad(4 \%)$ & Intermedia a NVP, EFV \\
& G190S & $1 \quad(4 \%)$ & Alta a NVP, EFV \\
& D67N & $1 \quad(4 \%)$ & Intermedia-Baja a AZT, D4T \\
K70R & $1 \quad(4 \%)$ & Intermedia-Baja a AZT \\
& V75T & $1 \quad(4 \%)$ & Intermedia a D4T, DDI \\
K103N & $1 \quad(4 \%)$ & Alta a NVP, EFV \\
Y188C & $1 \quad(4 \%)$ & Alta a NVP \\
A71V* & $1 \quad(4 \%)$ & Baja a todos los IP \\
& M36I* & $3 \quad(12 \%)$ & \\
L63P* & $6 \quad(24 \%)$ & \\
L10V* & $2 \quad(8 \%)$ & \\
K20R* & $1 \quad(4 \%)$ & \\
\hline
\end{tabular}

*Mutaciones polimórficas. Contribuyen a la resistencia sólo cuando se presentan en combinación con mutaciones mayores o con mutaciones accesorias.

drogas del grupo de los inhibidores análogos de nucleósidos de la transcriptasa reversa (ITRN), y V179D para drogas del grupo de los ITRNN. Cinco mutaciones fueron identificadas para la proteasa asociadas a resistencia intermedia/baja (A71V, L63P, M36I, L10V, K20R). La mutación más frecuente fue la L63P (6 pacientes), seguida de la M36I (3 pacientes) y la L10V (2 pacientes) básicamente polimórficas. En cinco pacientes se encontró más de una mutación, y tres de ellos presentaban tanto mutaciones en la transcriptasa reversa como en la proteasa.

Características epidemiológicas. Los pacientes que presentaron mutaciones de resistencia tenían títulos profesionales universitarios o habían cursado estudios superiores. La mayoría tiene residencia en comunas del área nororiente de Santiago y se encontraban realizando actividades asociadas a su profesión o de vacaciones en los lugares mencionados. Todos refieren haber mantenido conductas sexuales de riesgo, principalmente sexo desprotegido, o en asociación a la ingesta de alcohol y/o uso de drogas endovenosas (Tabla 4).

\section{DisCUSIÓN}

El desarrollo de terapia antirretroviral efectiva ha tenido resultados dramáticos en la disminución de la morbimortalidad por SIDA y ha trasformado esta infección desde una enfermedad rápidamente letal a una patología crónica, requiriente de un tratamiento complejo, de alto costo pero aún así, manejable? Los países desarrollados han implementado esta modalidad terapéutica masivamente en su población infectada en seguimiento con resultados muy favorables $^{3,} 10$. Este éxito ha tenido, sin embargo, consecuencias: una alta frecuencia de efectos tóxicos asociado a los esquemas de tratamiento y resistencia a las drogas antirretrovirales. Esta última es una de las principales barreras para lograr una supresión mantenida del virus durante la terapia.

En pocos años ha habido un incremento de la transmisión de cepas VIH-1 resistentes a la terapia antirretroviral. Un estudio reciente realizado por Shet y cols. ${ }^{11}$ reporta $24,1 \%$ de transmisión de resistencia en Nueva York en el período 20032004. Otros estudios reportan índices de resistencia primaria entre $3 \%$ y $29 \%^{12,13}$. Los individuos infectados con cepas VIH resistente a menudo tienen opciones limitadas dentro de los esquemas de terapia antirretroviral y pueden tener respuestas atenuadas a la terapia. Algunos estudios no evidencian cambios o disminución en los índices de resistencia primaria, por el contrario; otros muestran un incremento continuo ${ }^{12,14}$.

Este es el primer estudio que detecta resistencia primaria en pacientes bien documentados y 
Tabla 4. Antecedentes epidemiológicos de los pacientes con mutaciones de resistencia

\begin{tabular}{|c|c|c|c|c|c|}
\hline Paciente & Nivel Educacional & $\begin{array}{l}\text { Comuna de } \\
\text { residencia }\end{array}$ & Actividad laboral & $\begin{array}{l}\text { Actividad en lugar de } \\
\text { conducta de riesgo }\end{array}$ & Conducta de riesgo \\
\hline 1 & $\begin{array}{l}\text { Universitario } \\
\text { Completo }\end{array}$ & Santiago & Profesional & Congreso Profesional & Sexo desprotegido \\
\hline 2 & $\begin{array}{l}\text { Universitario } \\
\text { Completo }\end{array}$ & Providencia & Profesional & $\begin{array}{l}\text { Curso de } \\
\text { Perfeccionamiento }\end{array}$ & Sexo desprotegido \\
\hline 3 & $\begin{array}{l}\text { Universitario } \\
\text { Completo }\end{array}$ & Providencia & Profesional & Vacaciones & Sexo grupal desprotegido \\
\hline 4 & $\begin{array}{l}\text { Universitario } \\
\text { Completo }\end{array}$ & Ñuñoa & Profesional & Trabajo & Sexo desprotegido \\
\hline 5 & $\begin{array}{l}\text { Universitario } \\
\text { Completo }\end{array}$ & Providencia & Profesional & Trabajo/Vacaciones & Sexo desprotegido \\
\hline 6 & $\begin{array}{l}\text { Universitario } \\
\text { Completo }\end{array}$ & Huechuraba & Profesional & $\begin{array}{l}\text { Curso de } \\
\text { perfeccionamiento }\end{array}$ & Sexo desprotegido \\
\hline 7 & $\begin{array}{l}\text { Universitario } \\
\text { Incompleto }\end{array}$ & Santiago & Empresario & Trabajo & Sexo desprotegido \\
\hline 8 & $\begin{array}{l}\text { Universitario } \\
\text { Completo }\end{array}$ & Santiago & Profesional & Trabajo & Sexo desprotegido \\
\hline 9 & $\begin{array}{l}\text { Universitario } \\
\text { Completo }\end{array}$ & Vitacura & Cesante & Vacaciones & $\begin{array}{l}\text { Sexo desprotegido- } \\
\text { Uso drogas endovenosas }\end{array}$ \\
\hline 10 & $\begin{array}{l}\text { Universitario } \\
\text { Completo }\end{array}$ & Providencia & Profesional & Feria Internacional & Sexo grupal desprotegido \\
\hline
\end{tabular}

vírgenes a drogas antirretrovirales en Chile. Existe un estudio previo en Chile de resistencia primaria, realizado por nuestro grupo, entre los años 2001 y 2002, que analiza datos de 60 pacientes que se controlaban en el área norte de Santiago. Toda la población en estudio presentaba infección VIH/ SIDA crónica y no habían recibido drogas antirretrovirales. Ninguna de las mutaciones encontradas se asoció a un alto grado de resistencia a inhibidores de la transcriptasa reversa análogos de nucleósidos (ITRN), no análogos de nucleósidos (ITRNN) o inhibidores de la proteasa viral (IP) ${ }^{8}$.

En esta oportunidad, nuestro estudio se realizó con 25 pacientes, todos provenientes de la ciudad de Santiago, con diagnóstico reciente de infección VIH y vírgenes a terapia antirretroviral, poniendo especial énfasis en antecedentes como el tiempo transcurrido entre el momento de la infección y la realización del test de genotipificación, importantes para poder detectar de manera efectiva mutaciones de resistencia primaria en nuestro país, ya que los resultados son más confiables al estudiar pacientes con infección aguda o con infección reciente ( $<12$ meses), a diferencia de lo que ocurre al estudiar pacientes crónicos $^{14}$. Ello se explicaría por la mayor capacidad replicativa de la cepa sensible del virus respecto a una cepa mutada, lo que en infecciones de larga data termina enmascarando a las partículas virales que presentan mutaciones de resistencia.

Un total de 7 mutaciones fueron identificadas en la transcriptasa reversa. Tres mutaciones asociadas a alto nivel de resistencia (K103N, G190S, Y188C) y cuatro mutaciones asociadas a resistencia intermedia/baja (V179D, D67N, K70R, V75T). Cinco mutaciones fueron identificadas para la proteasa asociadas a resistencia intermedia/baja (A71V, L63P, M36I, L10V, K20R) que corresponden principalmente a mutaciones polimorfas. Además, en este estudio se rescataron antecedentes epidemiológicos y socioculturales, de manera similar a lo realizado en algunos estudios europeos y norteamericanos $^{15-19}$. Dentro de los antecedentes epidemiológicos es importante destacar que los pacientes en que se detectaron mutaciones, habrían adquirido la infección por VIH en ciudades 
del extranjero debido principalmente a conductas de alto riesgo llevada a cabo en esos lugares (Sexo desprotegido o "Bareback", y/o uso de drogas endovenosas). Las zonas donde los pacientes habrían adquirido la infección presentan prevalencias de resistencia primaria de un orden mayor a $10 \%$ de la población infectada por $\mathrm{VIH}^{15-19}$. Es interesante destacar que todos los pacientes infectados en que se detectaron mutaciones corresponden a personas con un nivel educacional superior, pertenecientes a un estrato socioeconómico alto, y la mayoría con domicilio en el sector nororiente de Santiago.

Respecto a esto se podría deducir que los pacientes de un nivel socioeconómico alto, que tiene acceso a visitar lugares en el extranjero, ya sea por motivos laborales o personales, y que tiene conductas de riesgo en esos lugares, estarían ingresando cepas resistentes de VIH a nuestro país. Las consecuencias que pueden traer estos hallazgos en la población chilena son preocupantes, dado el alto flujo de personas que experimentan viajes a zonas con elevados índices de

\section{REFERENCIAS}

1. UNAIDS. ONUSIDA. AIDS epidemic update: noviembre 2006. Disponible en: http:// www.who,int\&hiv

2. CONASIDA. Caracterización epidemiológica del VIH/SIDA en Chile a diciembre de 2005. Disponible en: http://www.conasida,cl/, http:// www.minsal.cl, consultado en marzo de 2007.

3. Wolff M, Beltrán C. Programa de acceso ampliado a terapia antirretroviral en Chile, Plan Auge y Cohorte Chilena de SIDA: Tres iniciativas complementarias. Rev Chil Infect 2004; 21: 281-4.

4. Turner D, Wainberg M. HIV Transmission and Primary Drug Resistance. AIDS Reviews 2006; $8: 17-23$.

5. Weinstock HS, Zaidi I, Heneine W. The epidemiology of antiretroviral drug resistance among drugnaive HIV-1 infected persons in 10 US cities. J Infect Dis 2004; 189: 2174-80.

6. Wensing AMJ, Van de Vijver DA, Angarano G. Prevalence of drug-resistant HIV-1 variants in untre- resistencia para el VIH, y que probablemente están teniendo conductas de riesgo. Muchas de estas personas pueden contagiar con cepas de VIH resistentes a sus parejas sexuales chilenas, e iniciar así la propagación de estas cepas por nuestro país, trayendo como consecuencia un gran impacto en la salud pública.

Como se comentó anteriormente, en el estudio previo realizado por nuestro grupo el año 2002, no se detectaron mutaciones de resistencia primaria en 60 pacientes del área norte de Santiago, sin embargo la principal diferencia de esos resultados con los que aquí presentamos radicaría en el nivel socioeconómico y estilo de vida de ambos grupos de pacientes.

Por lo anterior, resulta relevante establecer la real prevalencia de resistencia primaria en Chile, por lo que es necesario realizar estudios que contemplen un mayor número de pacientes, provenientes de todos los sectores sociales del país, para así obtener datos que reflejen la realidad nacional y sean útiles en el momento de establecer normas y recomendaciones nacionales para el manejo de nuestros pacientes. ated individuals in Europe: implications for clinical management. J Infect Dis 2005; 192: 958-66.

7. D'Aquila R. Incorporating Antiretroviral Resistance Testing Into Clinical Practice. Mesdcape CME Circle 2002-2003.

8. Afani A, Ayala M, Meyer A, Acevedo W, Cabrera R. Resistencia primaria a terapia antirretroviral en pacientes con infección por VIH/SIDA en Chile. Rev Méd Chil 2005; 133: 295-301.

9. Palella FJ, Delaney KM, Moorman aC. Declining morbidity and mortality among patients with advanced human immunodeficiency virus infection. HIV Outpatient Study Investigators. N Engl J Med 1998; 338: 853-60.

10. Petroni A, Deluchi G, Pryluka D. Update on Primary HIV-1 Resistance in Argentina: Emergence of Mutations Conferring High-Level Resistance to Nonnucleoside Reverse Transcriptase Inhibitors in Drug-Naive Patients. J Acquir Immune Defic Syndr 2006; 42: 506-10

11. World Health Organization, Joint United Nations Programme on HIV/AIDS. Treating 3 million by 
2005: making it happen: the WHO strategy. Geneva: World Health Organization, Joint United Nations Programme on HIV/AIDS; 2003.

12. Mark O. Primary HIV Drug Resistance and Efficacy of First-Line Antiretroviral Therapy Guided by Resistance Testing. J Acquir Immune Defic Syndr 2006; 41: 573-81.

13. GrubB J. Patterns of primary antiretroviral drug resistance in antiretroviral-naive HIV-1-infected individuals in a midwest university clinic. AIDS 2006; 20: 2115-25.

14. Little S, Holte S, Routy J, Daar E, Markowitz M, COLLIER A. Antiretroviral-Drug Resistance among patients recently infected with HIV. N Engl J Med 2002; 347: 385-94.

15. Viani R. Prevalence of Primary HIV-1 Drug Resistance among Recently Infected Adolescents: A Multicenter Adolescent Medicine Trials Network for HIV/AIDS Interventions Study. J Infect Dis 2006; 194: 1505-9.

16. UK Group on Transmitted hiV Drug Resistance. Time trends in primary resistance to HIV drugs in the United Kingdom: multicentre observational study. BMJ 2005; 331; 1368.

17. García-Guerrero J, Sáiz de la Hoya P, Portilla J. Prevalence of HIV-1 drug resistance mutations among Spanish prison inmates. Eur J Clin Microbiol Infect Dis 2006; 25: 695-701.

18. SHET A. Tracking the Prevalence of Transmitted Antiretroviral Drug Resistant HIV. J Acquir Immune Defic Syndr 2006; 41:439-46.

19. Babic D, Zelnikar M, Seme K, Vandamme A, Snoeck J, Tomazic J. Prevalence of antiretroviral drug resistance mutations and HIV-1 non-B subtypes in newly diagnosed drug-naive patients in Slovenia, 2000-2004. Virus Research 2006; 118: 156-63. 